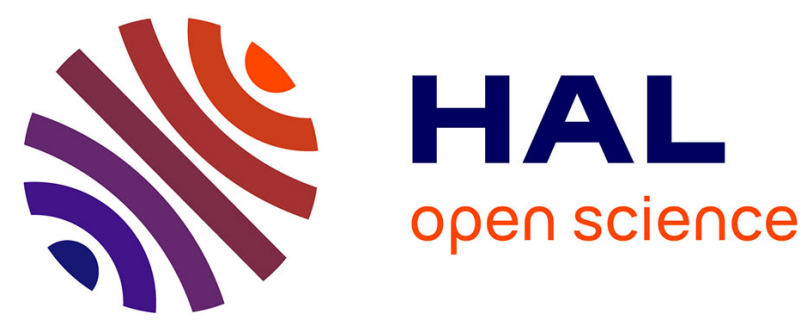

\title{
SURFACE LATTICE DYNAMICS OF NICKEL
}

\author{
V. Bortolani, A. Franchini, F. Nizzoli, G. Santoro
}

\section{To cite this version:}

V. Bortolani, A. Franchini, F. Nizzoli, G. Santoro. SURFACE LATTICE DYNAMICS OF NICKEL. Journal de Physique Colloques, 1981, 42 (C6), pp.C6-831-C6-833. 10.1051/jphyscol:19816245 . jpa00221331

\section{HAL Id: jpa-00221331 https://hal.science/jpa-00221331}

Submitted on 1 Jan 1981

HAL is a multi-disciplinary open access archive for the deposit and dissemination of scientific research documents, whether they are published or not. The documents may come from teaching and research institutions in France or abroad, or from public or private research centers.
L'archive ouverte pluridisciplinaire HAL, est destinée au dépôt et à la diffusion de documents scientifiques de niveau recherche, publiés ou non, émanant des établissements d'enseignement et de recherche français ou étrangers, des laboratoires publics ou privés. 
JOURNAL DE PHYSIQUE

Colloque 66 , supplément an $n^{\circ} 12$, Tome 42 , décembre 1981

page $\quad 66-831$

\title{
SURFACE LATTICE DYNAMICS OF NICKEL
}

\author{
v. Bortolani, A. Franchini, F. Nizzoli and G. Santoro \\ Istituto di Fisica and G.N.S.M.-C.N.R., Università di Modena, 41100 Modena, \\ Italy
}

\begin{abstract}
In the framework of a central and angular force constants rodel, we have evaluated the phonon spectrum and the loss function of the Ni(111) surface covered with oxigen. We explain quantitatively the main features of the observed electron energy loss spectra.
\end{abstract}

1. Introduction. - In this work we are intexested in the surface optical phonons of the $\mathrm{Ni}(111)$ surface for which very accurate high resolution electron energy loss (EE LS) experiments are available ${ }^{(1)}$. The detection of these surface vibrations with EELS occurs through the dipole coupling. The dipole is provided by fraction of monolayers of oxigen adsorbed on the metallic surface. As a consequence there are problems of interpretation of the experimental spectra because one has to discriminate between the modes of the substrate and the modes induced by the adsorbate. In order to solve this problen we show here that a realistic surface phonon calculation is needed. Our results indicate that the observed peaks relate to the phonons of the substrate for the Rayleigh wave, but otherwise are due to the adsorbed layer.

2. Calculation of the EELS spectrum.- In the dipole coupling approximation, the EELS scattering cross section has the form:

$$
\frac{d o}{d \Omega_{S}} \propto \frac{k_{B} T}{\omega^{2}}\left|\frac{w_{z}\left(\vec{Q}_{11}, l_{z}=0, \omega\right)}{\sqrt{m_{1}=0}}-\frac{w_{z}\left(\vec{Q}_{1, l_{z}}=1, \omega\right\rangle}{\sqrt{m_{1}=1}}\right|^{2}
$$

Here $w_{z}$ is the normal component of the polarization vector of the excited phonon with parallel momentum $\vec{Q}_{k}$ and frequency $\omega_{0} l_{z}$ labels the atomic planes and $m_{1}$ is the mass of the atoms in the $l_{z}$ plane. It is clear from this equation that the modes which are detectable are those having a non zero normal component of the sum of the polarization vectors in the surface unit cell. In order to evaluate the surface phonon field of $\mathrm{Ni}$ we use the slab method, in the framework of a central and angular force constants parametrization (2). We present here the calculations for the measured EELS spectra relative to the $\mathrm{Ni}(111): \mathrm{O} \mathrm{p}(2 \times 2)$ and to the $\mathrm{Ni}(111): 0(\sqrt{3} \times \sqrt{3}) \mathrm{R} 30^{\circ}$ geometries, depicted in Fig. 1. In both configurations the oxigen is bound to three $N_{1}$ in a $C_{3 v}$ position.

We firstly consider the $p(2 \times 2)$ geometry. In this case the $M$ point of the 2 -dimen sional Brillouin zone of the ideal (111) surface is folded in $\Gamma$, so that EELs detects the $M$ phonons. The experimental results ${ }^{(1)}$ are reported in Fig.2a. Three peaks are 


\section{NI (111):O $p(2 \times 2)$}

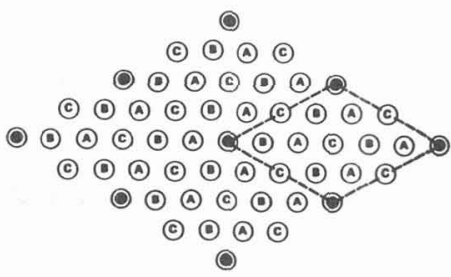

$N I(111): O(v 3 \times v 3) R 30^{\circ}$

(4)

(A) $\mathrm{Q}$ (-) (A)

(A) (c) 9 ( ) ( $)$ (A)

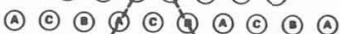

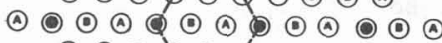

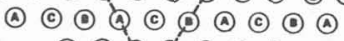

(A) (c) Q (c) ( )

(A) (2) (a) (a)

(A)

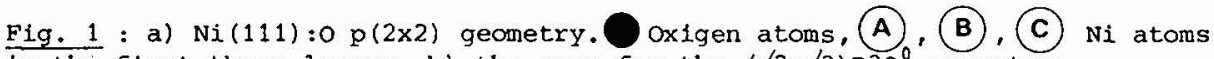
in the first three layers. b) the same for the $(\sqrt{3} \times \sqrt{3}) \mathrm{R} 30^{\circ}$ geometry.

present. The one at $72 \mathrm{mev}$, which is far outside the phonon spectrum of $\mathrm{Ni}$, is clearly due to the motion of the oxigen relative to the three coordinate Ni atoms. It cor. responds to the $A_{1}$ normal mode of a pyramidal $x_{3} y$ molecule ${ }^{(3)}$. As it can be seen from Fig.3, this mode gives a dipole moment along the $\mathrm{C}_{3 \mathrm{v}}$ axis, i.e. the surface normal. The lowest peak can be interpreted in terms of the surface phonons of the clean Ni (111) surface ${ }^{(2)}$. In fact, near this frequency there is the Rayleigh wave of the $M$ point which is mainly polarized normal to the surface. The other peak at $32.8 \mathrm{mev}$, inside the phonon spectrum of $\mathrm{Ni}$, cannot be explained in terms of the phonons of the clean surface. The modes of the $M$ point around this frequency are longitudinal and ds not couple with the impinging electrons. To clarify the nature of this peak we have performed a full calculation of the phonons of the covered surface. We have considered the interaction of oxigen with the three nearest nelghbouring Ni atoms by introducing one central and one angular force constant. By any arbitrary choice of these force constants the calculated EELS cross section shows three structures. The one at lowest frequency remains related to the Rayleigh mode of the substrate. The other two peaks are connected with the $A_{1}$ (higher frequency peak) and $A_{2}$ (central peak) modes of the $x_{3} y$ molecule. For this molecule, the frequency of the $A_{1}$ mode is mainly due to the value of the Ni-O central force constant, while the frequency of $\mathrm{A}_{2}$ depends on the Ni-O-Ni angular force constant. To determine the force constants of the $x_{3} y$ molecule we note that, even if the free $\mathrm{Ni}_{3} \mathrm{O}$ molecule does not exist, the surface potential is able to stabilize such a molecule. By using the EELs data relative to a very low disordered coverage of oxigen we fit the peak at $72 \mathrm{mev}$ with the central force constant and the peak at $30 \mathrm{meV}$ with the angular force constant. The results obtainec with these parameters are reported in Fig. 2b. The lowest peak is still related to the Rayleigh wave of the clean surface. The presence of the oxigen atom does not modify the frequency and polarization of this mode. The highest peak remains at the energy position of the $A_{1}$ mode of the molecule. The other peak at $32.8 \mathrm{mev}$, in perfect agreement with the experiment, results slightly shifted with respect to the energy of the $A_{2}$ mode of the free molecule, while the polarization remains the same. The frequency shift can be undexstood in terms of the indirect $0-0$ interaction caused by the sub- 
Ni(111):O $p(2 \times 2)$

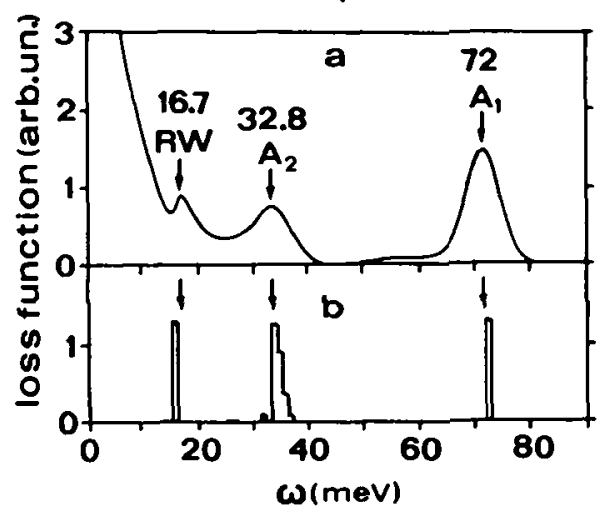

$\mathrm{Ni}(111): \mathrm{O}(13 \times / 3) \mathrm{R} 30^{\circ}$

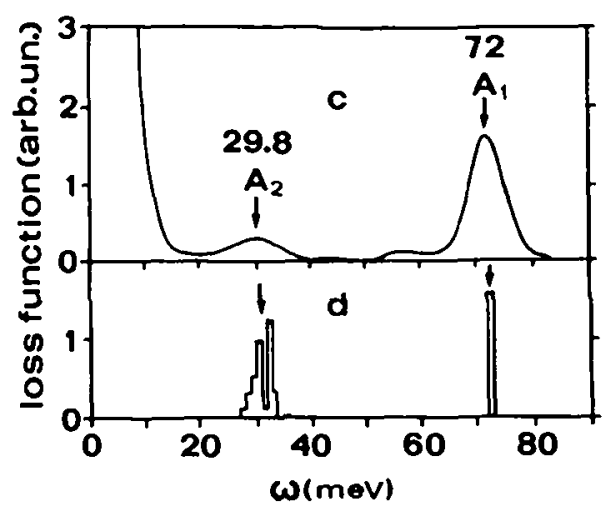

Fig. 2 : a) and b) experimental and calculated EELS intensities for the $p(2 \times 2)$ geometry. c) and d) the same for the $(r / 3 \times \sqrt{3}) \mathrm{R} 30^{\circ}$ geometry.

strate.

The same analysis has been carried out for the $(\sqrt{3} \times \sqrt{3}) R 30^{\circ}$ geometry. The experimental and calculated intensities are compared in Fig. $2 \mathrm{C}$ and Fig. 2 d respectively. The two observed modes are related to the $A_{1}$ and $A_{2}$ modes of the molecule. The 29.8 mev peak is slightly shifted with respect to the corresponding mode of the $p(2 \times 2)$ geometry because of the different $0-0$ interaction.

In conclusion, we have shown that

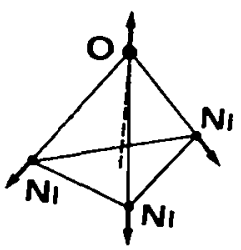

A,

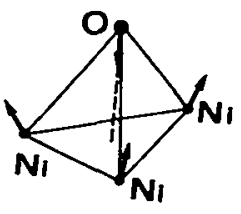

$\mathbf{A}_{2}$

a detalled calculation allows to explain the loss spectra of coated systems and to identify the origin of the eperimental stuctures in terms of the modes of the substrate and those of the adsorbate species.

\section{References}

1) H Ibach and D Bruchmann, Phys.Rev. Lett. 44, 36 (1980)

2) V Bortolani, A Franchini, F Nizzoli and $\vec{G}$ Santoro, Proccedings of the summer School on the Dynamics of Gas-Surface Interaction, Erice (1981), to be published

3) G Herzberg, "Molecular spectra and molecular structure" vol.2, p.155, Van Nostrand Inc., New York (1945) 